\title{
Diversidade linguística, direitos linguísticos e planificação linguística em Moçambique: problemática e desafios na adoção da língua de instrução no ensino e aprendizagem
}

\author{
Maria Helena de Paula ${ }^{a}$ \\ Zacarias Alberto Sozinho Quiraque
}

\begin{abstract}
Resumo
Moçambique é um país multilíngue, plurilíngue e multicultural, onde cerca de 20 linguas são classificadas como Bantu, com características específicas, mas correlatas. Destas, a mais falada é usada por $26 \%$ da população, uma das razões por que Moçambique está entre os vinte e cinco países africanos com diversidade linguística acentuada. A questão que se coloca é que língua adotar para o ensino de modo a que se respeitem os direitos linguísticos de cada indivíduo de receber a educação na sua língua materna. Para respondê-la, (1) discutimos a adoção do português como única língua de ensino e disciplina desde o período pós-independência, (2) analisamos criticamente os dois modelos de educação (monolingue e bilingue) e (3) propomos estratégias como desafio rumo à melhoria do processo de ensino e aprendizagem do país. A pesquisa bibliográfica e a introspeção embasam o estudo, que conduz ao posicionamento de que Moçambique precisa de um modelo que promova um bilinguismo inicial desde os primeiros anos de escolaridade, prevendo continuidade no uso das línguas bantu nas classes subsequentes ao ensino primário, distintamente do que tem ocorrido no ensino moçambicano. Para tal, é preciso incutir conhecimentos sólidos nos formandos dos Institutos de Formação de Professores (IFP) na matéria de educação bilingue, sem esquecer de capacitar os professores em exercício na mesma matéria, oferecendo ao cidadão moçambicano o gozo de parte dos direitos linguísticos estabelecidos em 1996 pela Organização das Nações Unidas para Educação, Ciência e Cultura (UNESCO).
\end{abstract}

Palavras-chave: Diversidade Linguística. Direitos Linguísticos. Lingua de ensino.

\footnotetext{
aDoutora em Linguística e Língua Portuguesa pela UNESP/Araraquara (2007), docente da Universidade Federal de Goiás. E-mail: mhp.ufgcatalao@gmail.com

${ }^{b}$ Docente na Universidade Eduardo Mondlane (Moçambique), atualmente cursa Mestrado em Estudos da Linguagem na Universidade Federal de Goiás/Regional Catalão. Bolsista do CNPq, pelo PEC-PG. E-mail: quiraque@gmail.com
} 


\section{Considerações iniciais}

O multilinguismo, o plurilinguismo e o multiculturalismo são algumas caraterísticas de vários países de África. Segundo Van e Craen e Perez-Vidal (2003, apud CAPUCHO, 2006), em algumas literaturas anglo-saxônicas, o multilinguismo se refere a sociedades onde é falada mais de uma língua, oficial ou não, enquanto o plurilinguismo se refere ao fato de um indivíduo falar mais de uma língua. As diversas línguas coexistentes, porém, raramente têm a mesma função, devido a vários fatores.

Em Moçambique, mais de 20 línguas autóctones bantu coexistem (SITOE, 2016), não só com a língua portuguesa, mas também com outras várias línguas de origem asiática. Após a proclamação da independência, o país tem vivido diversas mudanças no que concerne à sua estrutura econômica, política, social, administrativa e educacional.

A questão que se coloca na área de educação, como reflexão deste trabalho é: que língua adotar para o ensino de modo a que se respeitem os direitos de cada indivíduo de receber a educação na sua língua materna, como estabelecido pela Declaração Universal dos Direitos Linguísticos (UNESCO, 1996)?

Este estudo tem como objetivos (1) discutir a adoção, desde a independência em 1975, da língua portuguesa, língua oficial, como único meio de ensino e disciplina no processo de ensino e aprendizagem e as tendências atuais de incluir as línguas bantu nesse processo em algumas comunidades de Moçambique; (2) analisar criticamente os dois modelos de educação (monolíngue e bilíngue) mostrando que o primeiro tende a ser excludente, na perspectiva de língua como direito, enquanto na segunda modalidade transparece o assimilacionismo e (3) propor estratégias como desafio rumo à melhoria do ensino naquele país.

Para responder à questão de reflexão acima e alcançar os objetivos do estudo, foi feita vasta pesquisa bibliográfica sobre a diversidade linguística, direitos linguísticos e os diferentes modelos que estão sendo usados no processo de ensino e aprendizagem em Moçambique, além de reportar à Declaração Universal dos Direitos Linguísticos, (DUDL, doravante) proposta pela UNESCO (1996). Porém, porque um dos autores do estudo é conhecedor da implementação 
destes modelos de ensino, no contexto em alusão, recorreu-se também à introspeção na verificação e análise dos dados e posicionamento crítico sobre a questão fulcral do estudo.

\section{Diversidade linguística em Moçambique}

Como já referido, à semelhança de muitos países, Moçambique é um caso típico de país multilíngue, plurilíngue e multicultural. Essas características devem-se ao fato de ser um país onde se falam várias línguas que servem a várias culturas, que, para além de serem usadas na comunicação diária, constituem línguas maternas e mais utilizadas na condução da vida do dia a dia de mais de $80 \%$ da população moçambicana.

Esse fato faz com que esse país faça parte dos vinte e cinco países da África com diversidade linguística acentuada ou elevada. Na perspectiva de Robson (1993, apud MABASSO, 2010), considera-se elevada diversidade linguística a situação em que uma percentagem não superior a $50 \%$ da população de um país fala a mesma língua. "Esta situação pressupõe que o grau de diversidade linguística seja calculado não a partir do número total de línguas faladas num determinado país, mas sim em termos da percentagem da população que fala a língua tomada singularmente" (ROBINSON, 1993, p. 52, citado por MABASSO, 2012, p. 41). Assim, o Makhuwa, língua autóctone com mais falantes como L1, representa aproximadamente $26.1 \%$ da população total.

Por seu lado, o português, língua oficial do país registrou nos últimos 30 anos um crescimento em termos de falantes, como L1 e como L2. Na primeira condição (como L1), passou dos 1.2\% em 1980 para 10.7\% em 2007 e, como língua segunda (L2) passou dos $23 \%$ para $40 \%$. Consideram-se os 5 anos como idade mínima de referência, tomada pelo Instituto Nacional de Estatística (INE), para definir uma pessoa como falante de uma língua (NGUNGA; BAVO, 2011).

Dezessete anos depois de ponderar a existência de dois grupos de línguas em Moçambique (línguas bantu moçambicanas e as línguas portuguesa, inglesas e asiáticas, tidas como estrangeiras), Firmino (2015) considera o português como língua autóctone e não estrangeira como defendera em 1998. Nesse último estudo, ele defende que 
Em Moçambique, existem bolsas de falantes de outras línguas de origem estrangeira, que não sejam o português, principalmente o inglês, e outras de origem asiática, como o hindi, urdi ou gujrati. O inglês é falado com e pela comunidade de estrangeiros ligada a organizações internacionais e embaixadas, embora, devido aos contatos com países limítrofes, como, por exemplo, a República da África do Sul, haja muitos moçambicanos que usam frequentemente esta língua. As línguas de origem asiática são faladas entre membros da comunidade emigrantes, oriundos principalmente do continente asiático (principalmente, Índia e Paquistão) ou seus descendentes (FIRMINO, 2015, p. 127).

Entende-se que a tendência atual da não inclusão do português como língua estrangeira deve-se não só ao aumento da população falante dessa língua como materna, mas também às evidências mostradas por vários estudos moçambicanos (FIRMINO, 2002 [1995]; GONÇALVES, 2010; MARIANI, 2011; LOPES, SITOE e NHAMUENDE, 2002, todos citados por FIRMINO, 2015 entre outros), que apontam a sua nativização no contexto do uso de um português falado em Moçambique. Essa nativização pode ser vista como consequência da sua apropriação social (FIRMINO, 2015), o que condicionou a sua transformação estrutural e, sobretudo, sócio-simbólica.

Nesse sentido, tanto os dados de 2007 como os de 2017 adiante apresentados deixam claro que a maioria da população moçambicana vive no campo e conduz as suas vidas em línguas bantu. E essa população também precisa de igual atenção à da população das zonas urbanas, o que sugere traçar políticas linguísticas com vista à valorização das línguas e culturas das massas nos serviços de administrações públicas e outros contextos oficiais, incluindo o processo de ensino e aprendizagem dos alunos.

Para que se adotem políticas linguísticas que incitam a

${ }^{1}$ Planificação linguística é usada, neste estudo, como planejamento linguístico, que considere as diferenças e as respeite sem buscar anular as diversidades linguísticas e culturais; ao contrário, para a planificação aqui referida, as diversidades e diferenças linguísticas e culturais devem centrar esta política. uma planificação ${ }^{1}$ linguística adequada para beneficiar o povo moçambicano no gozo dos seus direitos (a exemplo do que propõe a DUDL da UNESCO, em 1996), é preciso que essas leis sejam plasmadas, de forma clara, em documentos oficiais. Segundo Firmino:

Apesar de serem amplamente usadas para a comunicação quotidiana intra-ética, nas zonas rurais quase exclusivamente e nas urbanas juntamente com o português, não se reconhece nenhum estatuto oficial explícito às línguas autóctones, excetuando o facto de inúmeros discursos oficiais e/ou 
públicos se referirem à sua importância, principalmente na sua condição de repositório da herança cultural moçambicana. (FIRMINO, 2015, p. 126),

Tanto na Constituição de 1990 (Título I, capítulo I, artigo 5. 1) como na de 2004 (artigo 10), somente se consagrou a oficialização do português, sem que, contudo, se explicitassem as funções das outras línguas, o que faz com que até hoje a maioria da população dominada seja excluída de atividades administrativas oficiais e de educação, com perdas de todos níveis para o governo e, sobretudo, para o povo moçambicano.

São várias as questões apresentadas e que preocupam a muitos moçambicanos sobre a integração e valorização das suas línguas em contextos de serviços administrativos. Em um futuro breve, tendo em conta a diversidade linguística desse país, sobretudo da maioria da população vivendo nas zonas rurais, para 2017, quando se prevê a realização do quarto recenseamento populacional, o INE estima que a população moçambicana se eleve a um total de 27.128 .530 de habitantes, sendo 18.361 .753 das zonas rurais, 8.766 .777 de população urbana, e 13.106.447 sejam homens e 14.022.083, mulheres.

\section{Breves considerações sobre direitos linguísticos}

A Comissão Nacional da UNESCO, no cumprimento do seu objetivo de contribuir para a paz no mundo, juntamente com as instituições e organizações não governamentais, entre os dias 6 e 9 de junho de 1996, em Barcelona, elaboraram a Declaração Universal dos Direitos Linguísticos, a DULD.

Foi com base na Declaração Universal dos Direitos do Homem de 1948, que estabelece, no seu artigo 2, que "todos têm todos os direitos e todas as liberdades", sem distinção "de raça, cor, sexo, língua, religião, opinião política ou outra, origem nacional ou social, fortuna, nascimento ou qualquer outra condição" (UNESCO, 1996), que os direitos linguísticos universais foram estabelecidos, para "permitir a correção dos desequilíbrios linguísticos com vista a assegurar o respeito e o pleno desenvolvimento de todas as línguas e estabelecer os princípios de uma paz linguística planetária justa e equitativa, como fator fundamental da convivência social" (UNESCO, 1996). 
Nessa perspectiva, por um lado, no seu artigo terceiro $\left(3^{\circ}\right)$, item um (1), a DUDL da UNESCO

considera como alguns direitos individuais inalienáveis que devem ser exercidos em todas as situações os seguintes: o direito ao uso do próprio nome; o direito a ser reconhecido como membro de uma comunidade linguística; o direito ao uso da língua em privado e em público; o direito a manter e desenvolver a própria cultura. (DUDL da UNESCO, 1996, grifo nosso)

Por outro lado, no item dois (2) do mesmo artigo (terceiro), considera como direitos coletivos dos grupos linguísticos que podem incluir ainda, em acréscimo aos estabelecidos no número anterior, os seguintes:

o direito ao ensino da própria língua e da própria cultura; o direito a dispor de serviços culturais; o direito a serem atendidos na sua língua nos organismos oficiais e nas relações socioeconómicas; o direito a uma presença equitativa da língua e da cultura do grupo nos meios de comunicação (UNESCO, 1996).

Esses direitos, individuais e coletivos para qualquer cidadão do mundo, independentemente da sua localização geográfica ou estrato social, devem ser garantidos e considerados por todos os governantes, a depender de cada contexto local, com vista a garantir que o cidadão use e se expresse livremente na língua que melhor entende preservando a sua identidade, sua cultura, sua autoestima e autoconfirmação.

Ademais, no caso de Moçambique, a valorização destes direitos é sempre questionada em várias literaturas até então, pois

[...] faltam coragem, iniciativa de, pelo menos, tentar implementar estas políticas, pois sabe-se que já existem estudos suficientes de linguistas e investigadores que mostram, de forma eficiente [e evidente], os problemas relacionados à política de suas línguas que Moçambique enfrenta para o seu desenvolvimento" (PAULA eQUIRAQUE, 2016, p. 1234).

Espera-se, pois que, em um futuro em curto prazo, o governo tenha vontade política para ouvir os resultados de vários estudos destes e de outros moçambicanos com vista a respeitar os direitos plasmados na DUDL da UNESCO. São estudos que clamam, para além do uso destas línguas em 
contextos institucionais, que sejam usadas também, na educação formal, principalmente no ensino e aprendizagem dos alunos.

No que tange ao ensino, dentre os vários direitos estabelecidos pela DUDL destacam-se os seguintes:

Artigo 23: 1. O ensino deve contribuir para fomentar a capacidade de autoexpressão linguística e cultural da comunidade linguística do território onde é ministrado; 2. O ensino deve contribuir para a manutenção e o desenvolvimento da língua falada pela comunidade linguística do território onde é ministrado; 3 . O ensino deve estar sempre ao serviço da diversidade linguística e cultural, e das relações harmoniosas entre as diferentes comunidades linguísticas do mundo inteiro.

Artigo 29: 1. Todos têm direito ao ensino na língua própria do território onde residem. 2. Este direito não exclui o direito de acesso ao conhecimento oral e escrito de qualquer língua que lhes sirva de instrumento de comunicação com outras comunidades linguísticas.

Um dos argumentos usado pelos governantes de Moçambique sobre o adiamento da impetração do ensino nas línguas nativas em todo o território nacional é o orçamento sobre o material escolar. Ou seja, para aquelas dirigentes, o governo teria que gastar o dobro ou o triplo de valores monetários para aquisição de material escolar para as 17 línguas que pelo menos já têm a sua ortografia padronizada. É preciso frisar que esse argumento fere os direitos da criança estabelecidos pela UNESCO na DULD, especialmente nos artigos 24,25 e 26.

Como se vê, a DUDL objetiva resguardar os direitos das várias línguas do mundo, até as em vias de extinção, menosprezadas ou deixadas em segundo plano, por vários governantes do mundo, usando diferentes argumentos e a depender de cada caso.

Outro argumento usado pelos governantes de Moçambique é que nenhuma das línguas autóctones daquele país é falada em todo território. Contudo, para este argumento, Paula e Quiraque (2016) já apresentaram uma proposta como hipótese para contribuir na solução deste problema, ao defenderem a inclusão, no artigo 10 da Constituição da República de Moçambique (doravante CRM), sobre as línguas oficiais, pelo menos três línguas autóctones bantu, as mais 
faladas do país (Machuwa, Changana, e Sena). Nas palavras destes autores, a proposta se configura como:

[...] para além de: “Na República de Moçambique a língua portuguesa é a língua oficial", como aparece no artigo 10 do mesmo documento, propomos, por exemplo: "Na República de Moçambique, a língua portuguesa $e$ as línguas bantu $M$, $C, S$ etc. são as línguas oficiais, e a utilização destas línguas deve considerar o contexto e as culturas de cada local" (PAULA e QUIRAQUE, 2016, p. 1232, com destaques no original).

Sobre as línguas bantu M, C, S mencionadas na proposta da inclusão de outras línguas faladas em Moçambique na sua Constituição, o $\mathbf{M}$ corresponde à língua Makhuwa, a mais falada do país e ainda a mais falada nas províncias da zona norte; o $\mathbf{C}$, à língua Changana, a que tem maior número de falantes na região sul, e o $S$, à língua Sena, a mais falada na região central (PAULA; QUIRAQUE, 2016).

Por se tratar de um começo de políticas linguísticas inclusivas em um país multilíngue e plurilíngue, a escolha de algumas línguas bantu para serem usadas cooficialmente com o português é viável, pois além de promover as práticas de intercompreensão das línguas bantu entre falantes que vivem em zonas linguisticamente homogêneas, abre um caminho para que, no futuro, outras línguas bantu sejam incluídas como cooficiais na CRM, valorizando a DUDL da UNESCO (1996).

Depois de tecidas algumas considerações sobre os direitos linguísticos universais, serão abordados a seguir a educação em Moçambique e os modelos de ensino e aprendizagem adotados para os programas educacionais para o país.

\section{Notas sobre a periodização da educação em Moçambique}

Todo o sistema de educação de um país tem uma história de administração que pode ser alterada de acordo com as reformas levadas a cabo para adequá-lo às condições socioeconômicas e políticas (UACIQUETE, 2011). Para esse autor, essas constantes alterações são consideradas como tentativas de busca de soluções para responder aos desafios colocados em um país em um dado contexto.

Moçambique é um país típico dos desafios mencionados no que concerne à reforma do sistema educacional. Muitos 
dos fracassos das alterações feitas partem da não definição de políticas consistentes nos documentos que incitam as leis mães para reger o país com vista a, a partir delas, traçar uma planificação adequada ao contexto e que coadjuvem com a realidade do país.

A administração do sistema de educação em Moçambique foi caraterizada por dois momentos: o pré-colonial e o pós-colonial. Na perspectiva de Uaciquete (2011), antes da Independência, há duas fases: a primeira, de uma educação colonial (1845 a 1974) e a segunda, uma educação do governo de transição após a guerra contra o colonialismo português (1974 a 1975). O segundo período é o de educação pós-independência, até então com três fases: a fase antes do Sistema Nacional de Educação (doravante SNE) entre os períodos de 1975 a 1982, seguida da primeira fase do SNE (1983 a 1991), e, por fim, a segunda fase do SNE, em vigor de 1992 até atualidade.

Ao diferenciar a educação dos dois períodos, antes e pós-independência, Mazula (1995, apud UACIQUETE, 2011) sublinha que a educação do sistema colonial baseava-se em teorias racistas e discriminatórias como a da carência cultural e defensora de relações coloniais-capitalistas, enquanto o sistema educativo pós-colonial baseava-se num projeto racional que procurava uma organização científica da cultura, baseando-se em algumas teorias da modernidade e tradição, mas desarticulados dos aspectos da cultura do povo. Nessa linha de ideias,

\begin{abstract}
a história de educação em Moçambique é descrita como tendo sofrido influências de "pesada herança colonial" em que a educação visava a dominação, a alienação e a cristianização dos "povos primitivos" e mais tarde com a luta de libertação nacional surge uma educação sob o signo de ruptura e de superação da educação "colonial" e "tradicional" seguida por uma fase em que a educação está ao serviço da construção de uma sociedade e de "um homem novo" e a favor dos interesses dos trabalhadores e camponeses moçambicanos (UACIQUETE, 2011, p. 23, grifos do autor).
\end{abstract}

No entanto, acrescenta o autor, a educação tem sido vista como estando assente num modelo fortemente centralizado, principalmente no período pós-independente, em que o país viveu uma situação de monopartidarismo, na qual estabelecer 
a separação e a distinção entre o partido no poder e o estado foi sempre problema em Moçambique.

Acrescenta-se que, a partir dos anos noventa, o país registrou uma tentativa de ruptura do regime de monopartidarização e o parlamento passou a ser composto não apenas por membros da Frente de Libertação de Moçambique (FRELIMO), mas também por membros da Resistência Nacional de Moçambique (RENAMO), além da entrada do Movimento Democrático de Moçambique (MDM) nos finais da primeira década do segundo milênio.

Apesar desse cenário, o partido no poder (FRELIMO) continua representado pela maioria no parlamento. $\mathrm{E}$ isso confirma que, apesar de se incluírem outros partidos naquela magna casa para discutirem e decidirem o rumo do país, na prática Moçambique ainda não é multipartidário no seu verdadeiro sentido, tornando as políticas não só educativas, mas também econômicas, sociais, linguísticas etc. repetitivas e sem inovações espelhadas nas novas dinâmicas e desafios que se colocam ao país. É nesse contexto que, nas próximas linhas serão discutidos os modelos que estão sendo utilizados para efetivar o processo de ensino e aprendizagem naquele país, amparados na perspectiva da diversidade linguística e direitos linguísticos mencionados.

3.1. Os programas vigentes no processo de ensino/ aprendizagem em Moçambique

Considerando a periodização da educação em Moçambique mencionada anteriormente (UACIQUETE, 2011), infere-se que desde o período pré-independência até o pós-independência (neste último entre os anos 1975 a 1997) Moçambique vem adotando, para o processo de ensino e reaprendizagem, um tipo de programa de educação que visa ao uso do português (única língua considerada oficial até então e de "unidade nacional") como o único meio de instrução/ensino e disciplina em todos os níveis de escolarização, caracterizado como o Programa de Educação Monolingue.

Está-se a falar de um período em que, segundo o primeiro Censo de 1980 e o de 1997, menos de $10 \%$ da população $(1.2 \%$ e $6.5 \%$, respectivamente) tinha o português como língua 
materna. Entretanto, essas políticas e planificação do ensino vinham beneficiando a maioria dominante em detrimento das massas, dominadas, que somente falavam/falam outras línguas, que não seja o português. Consequentemente, esse tipo de modelo registra(va) baixo nível de aproveitamento escolar e elevados índices de desistência das crianças que não tinham o português como L1 nas classes iniciais, fazendo que o governo moçambicano contabilizasse altas perdas no seu investimento.

Portanto, tratava-se/trata-se de um programa imposicionista para a maioria, mas tratada como minoria em termos de poder (PATEL, 2006), onde esta era/é forçada a aprender as matérias escolares numa língua (L2) alheia à sua socialização primária, o que culminava com vários desastres registrados no processo de ensino e aprendizagem entre o professor e o aluno.

Com a barreira linguística o aluno não pode partilhar as suas experiências com o professor e com os colegas, tampouco exprimir as suas ideias e emoções; não compreende a maior parte das instruções e explicações dadas pelo professor, porque a criança não fala a língua de instrução (DIAS, 2002). Nesse contexto, a falta de comunicação na sala de aulas e a descontinuidade entre o conhecimento oferecido pela escola e o que a criança traz de casa são algumas das desvantagens do uso exclusivo de uma língua segunda ou estrangeira na aprendizagem inicial da criança.

Um estudo das políticas e práticas linguísticas educacionais adotadas muito recentemente mostra que, em termos oficiais, a didática do ensino do português assentava na política de exclusão total das línguas moçambicanas da sala de aulas e não só (CHIMBUTANE, 2015).

Portanto era/é um programa excludente, do ponto de vista do processo de ensino e aprendizagem em Moçambique, à medida que não tinha/não tem em consideração as crianças que não tinham/não têm o português como a sua L1 nas primeiras classes de escolaridade, beneficiando a minoria dominante, pois só esta é que podia assimilar facilmente os conteúdos lecionados. Por isso, o programa de educação monolíngue é também considerado "elitista" e segregacionista, porque separa a maioria das crianças que não tem português como língua materna, da minoria "elitizada". É um programa que somente beneficia a minoria dominante, na medida em que só esta é que podia assimilar facilmente os conteúdos lecionados. 
O governo levou mais de duas décadas para acreditar nas literaturas que fundamentavam a importância do uso não só do português, mas também das línguas bantu de Moçambique no processo de ensino e aprendizagem. Somente nos anos 90 ele começou a pensar nas estratégias de introdução das línguas moçambicanas no ensino primário através do Instituo Nacional de Desenvolvimento de Educação (INDE). Assim, começa o processo piloto do uso das línguas autóctones como recurso no ensino, pois

Do ponto de vista estratégico, a introdução de línguas moçambicanas no ensino primário vai observar três modalidades: como meio de ensino-aprendizagem, em programas de educação bilíngue, como disciplina opcional em programas monolíngues em que o Português é meio de ensino e, como recurso, também, em programas em que o meio de ensino é a língua portuguesa, como L2 (INDE, s/d, p. 127, com grifos nossos).

Dentre as três modalidades patentes na citação acima, interessa-nos neste trabalho discutir sobre a primeira, isto é, o uso das línguas bantu, no programa de educação bilíngue, como meio de instrução/ensino na aprendizagem. Cabe salientar, contudo, que, segundo o INDE, essa modalidade, que deveria privilegiar o desenvolvimento de programas de educação em línguas bantu, tem como foco as zonas linguisticamente homogêneas ${ }^{2}$ que são, na sua maioria, zonas rurais.

Com uma reforma curricular do ensino primário $\left(1^{\mathrm{a}}\right.$ a $7^{a}$ classe) entre 1997-2003, passam, a partir desse momento, a coexistir dois programas de ensino: Programa de Educação Monolíngue e o de Educação Bilíngue - este como resposta à melhoria do ensino na alfabetização inicial do aluno, principalmente no ensino primário.

Os especialistas na matéria bilíngue levaram pouco mais de dez anos para mostrar ao governo e aos demais que

${ }^{2}$ Consideram-se zonas linguisticamente homogêneas aquelas em existem distintas línguas, que apresentam pequenas diferenças que não impedem àqueles que as usam de se compreenderem entre si. a educação bilíngue não devia ser interpretada como uma educação em línguas bantu, como se pensava; antes, é uma educação nessas línguas e em língua oficial (português), cada uma desempenhando funções específicas a depender de cada nível de escolarização primária. Dessa forma, o modelo de ensino bilíngue adotado pelo INDE chamou-se de modelo de transição gradual. 
Segundo os responsáveis pelos programas de ensino/ aprendizagem em Moçambique, a escolha desse modelo fundamentou-se em três razões: i) Razões linguísticopedagógicas: o aluno desenvolve com facilidade as habilidades cognitivas escolares ao ser ensinado na sua língua materna e, por sua vez, o professor terá mais autoconfiança para conduzir o processo de ensino-aprendizagem na sua língua nativa (INDE, s/d); ii) Razões culturais e de identidade: a língua materna usada para ensinar a criança vai funcionar como um veículo de transmissão de valores culturais e tradicionais (relação língua/cultura) no processo de ensino-aprendizagem, evitando-se uma descontinuidade entre os valores que a criança leva para a escola e os que ela vai adquirir (INDE, s/d); iii) A língua como direito: a efetivação dos direitos da DUDL da crianças só poderá tornar-se mais efetiva com o uso da sua língua materna no ensino/aprendizagem, paralelamente com a língua oficial (Português), de modo a promover-lhe um bilinguismo equilibrado.

Foi no âmbito dessas razões que se escolheu o modelo de transição gradual para o ensino bilíngue, como se traduz na figura 1 a seguir:

Figura 1. Modelo do Programa de Educação Bilíngue Adotado pelo INDE

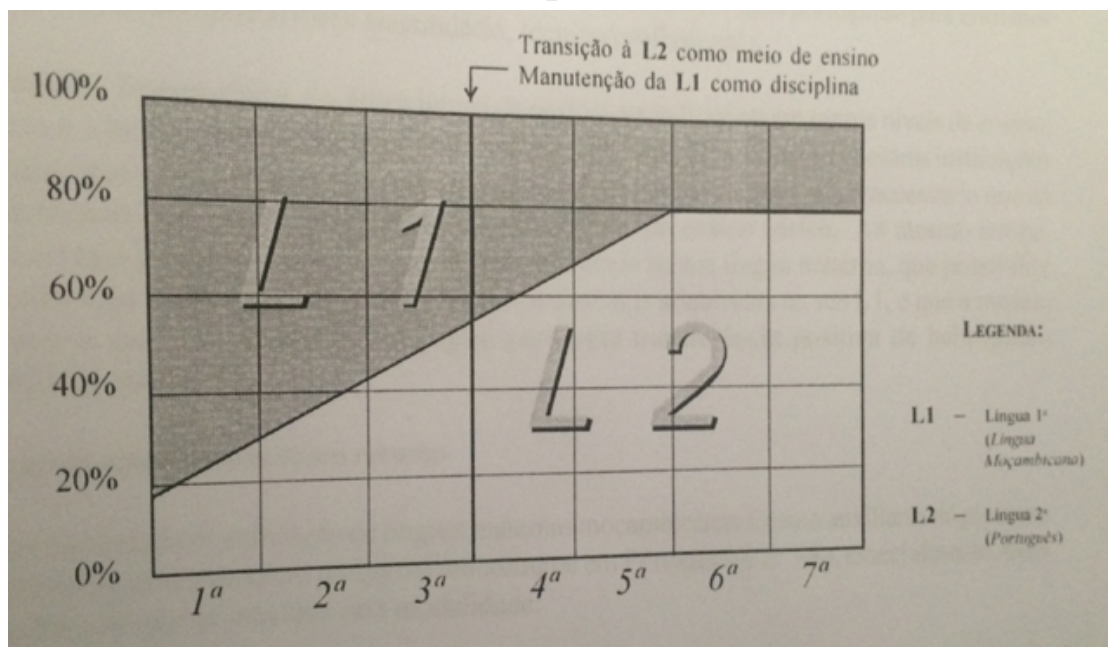

Fonte: INDE (s/d, p. 132) 
Segundo o INDE, o modelo acima se interpreta da seguinte maneira:

[No] primeiro Ciclo ( $1^{a}$ e $2^{a}$ classes), a língua materna do aluno é o único meio de ensino-aprendizagem, e, juntamente com o Português serão ensinados como disciplina, sendo o Português para desenvolver habilidades de oralidade para preparar a aprendizagem da leitura e da escrita nesta língua, no $2^{\circ}$ ciclo. [No] Segundo Ciclo $\left(3^{a}, 4^{a}\right.$ e $5^{a}$ classes $)$ inicia o processo de transição gradual do meio de ensino de L1 para a L2. Assim, no início da $3^{\text {a }}$ classe, [o meio de ensino-aprendizagem ainda é a L1] os alunos iniciam a aprendizagem da leitura e escrita em Português, através de um processo de transferência de habilidades adquiridas na sua L1; [...] a partir da $4^{\mathrm{a}}$ classe a L2 passa a exercer a função [...] [de meio de ensino e] a L1 passará a ser auxiliar do processo de ensino-aprendizagem, principalmente em disciplinas como Matemática, Ciências Naturais e Sociais, para clarificar conceitos difíceis. Tal como no primeiro, neste ciclo a L1 e a L2 são leccionadas como disciplina. [Por fim, no] Terceiro Ciclo ( $6^{a}$ e $7^{a}$ classes) a língua portuguesa é o único meio de ensino-aprendizagem [e também como disciplina] e a L1 será leccionada somente como disciplina, mas poderá, eventualmente, servir de auxiliar do processo de ensino e aprendizagem, à semelhança do que acontece em ciclos anteriores (INDE, s/d, p. 132).

Através do INDE, o Ministério de Educação e Desenvolvimento Humano (MINEDH) levou a cabo uma experimentação de educação bilíngue, que ditou as primeiras fases de implementação do modelo de transição gradual através de um projeto denominado Projeto de Escolarização Bilíngue em Moçambique (PEBIMO) entre 1993-1997, em duas províncias: Tete com línguas Nyanja e Português, e na província de Gaza com língua Changana e Português.

Os resultados desse projeto foram superiores quando comparados aos do ensino monolíngue em português. Segundo Benson (1997), do total de 357 alunos do primeiro ano de escolaridade ( $1^{\text {a }}$ classe) as percentagens indicavam $75 \%$ de aproveitamento positivo para o programa bilíngue e $50 \%$ para o programa monolíngue. Nas restantes classes do programa bilíngue indicava-se $85 \%$ de aproveitamento na $2^{\mathrm{a}}$ classe, $76 \%$ na $3^{\mathrm{a}}$ classe, $65 \%$ na $4^{\mathrm{a}}$ classe. Por fim, na $5^{\mathrm{a}}$ classe a experimentação terminou com um êxito de 200 alunos. Finda essa fase do 
PEBIMO, com esses bons resultados houve a necessidade de se alargar mais esse tipo de modelo.

Assim, depois do PEBIMO, foram introduzidos vários projetos que culminaram com inclusão de mais línguas e expansão desse tipo de ensino em mais escolas, também com bons resultados. Salienta-se, ainda, que, das mais de 20 línguas bantu em Moçambique, 17 já têm ortografia padronizada desde 1989 e possuem algum material escolar já escrito, incluindo livros do primeiro até sétimo ano de escolaridade ( $1^{\mathrm{a}}$ à $7^{\mathrm{a}}$ classe).

Atualmente, o país conta com várias associações responsáveis pela educação bilíngue. No Norte, há a Associação Progresso; em Gaza, a União para Desenvolvimento do Ensino Básico (UDEBA), em Manica e Sofala, a GTZ-LABE. Segundo o então ministro do MINEDH, Jorge Ferrão, atualmente o país conta com quinhentas e dez (510) escolas que lecionam o ensino bilíngue, prevendo-se o aumento de mais cento e setenta e nove (179) para $2017^{3}$.

\section{Problemas e desafios da língua de ensino à luz do modelo de educação bilíngue}

A primeira crítica que se pode observar na execução do modelo de transição gradual é o fato de ser um modelo com tendências ao assimilacionismo, ao forçar os alunos de minorias, ou maiorias tratadas como minorias, à assimilação da sociedade envolvente. Em Moçambique, é assimilacionista porque, principalmente na transição da L1 para L2 no segundo ciclo, o fim último é que a criança deixe de usar a sua língua materna em função da língua portuguesa. O modelo usa, pois, a língua bantu da criança como trampolim (uma ponte) para a aprendizagem e aperfeiçoamento do português.

Ademais, para resolver esse problema, Lopes (1997) já havia apelado para uma educação com um modelo de bilinguismo inicial. Ou seja, um modelo que prevê a utilização, desde o início da escolaridade, de uma língua bantu e o português

I $\mathrm{n} \mathrm{f}$ or m a ç ã o disponibilizada pelo jornal da noite da televisão moçambicana Stv, nodia 12 de setembro de 2016. Disponível em: $<$ https://www.youtube. com/watch? v=1-ijQI Og5I>. Acesso em: 12 set. de 2016. como meios de ensino e disciplinas e que os contextos de alternação (políticas de separação das línguas) no meio de ensino e aprendizagem devem depender de cada local.

Embora este modelo também seja de transição, o presente estudo apela à mudança do meio de ensino apenas em português nos níveis de escolarização mais avançados 
(na $7^{\mathrm{a}}$ classe, por exemplo) durante a escolarização, e não no terceiro ano ( $3^{\text {a }}$ classe) como o atual modelo de transição gradual prevê, uma vez que nesse ciclo a criança ainda não tem bases (competências linguísticas e comunicativas) suficientes da L2 (português) para que esta seja usada como único meio de ensino, considerando que ela entrou na primeira classe falando somente uma língua bantu. Isso fará com que se continue promovendo o direito da criança ao ensino através da sua língua materna (LOPES, 1997), seja língua bantu ou língua portuguesa, reduzindo futuros riscos de baixos níveis de proficiência linguística em classes mais avançadas.

A segunda observação que o modelo de transição gradual tem sofrido por alguns estudiosos (HAMEL, 1989; BAKER, 1993 apud PATEL, 2006) é o fato de se tratar de um modelo que conduz ao tipo de "Bilinguismo Subtrativo". No caso de Moçambique, à criança é concedido o direito de aprender na/ sobre a sua língua materna até o sétimo ano de escolaridade ( $7^{\text {a }}$ classe), e ao chegar ao oitavo ano ( $8^{\mathrm{a}}$ classe) é tirado dela esse direito ficando-lhe somente a língua segunda (L2) como meio de ensino e disciplina.

Trata-se, pois, de um modelo que não prevê a continuidade do gozo dos direitos da criança, de continuar a aprender e/ ou pelo menos ter a sua língua materna como disciplina no processo de ensino e aprendizagem nas classes subsequentes. Nesse sentido, ao retirar-lhe a sua língua materna (bantu) na oitava classe, automaticamente o modelo volta a pôr em causa o pressuposto dos artigos da DUDL do cidadão que, de antemão, pensou-se que já tivessem sido ultrapassados.

Portanto, deve-se desenhar ou procurar desenhar um modelo que preveja a inclusão da disciplina de línguas maternas (bantu) nas classes subsequentes ao ensino básico ( $8^{\circ}$ ao $12^{\circ}$ ano de escolaridade) de modo que as línguas bantu enriqueçam o português falado em Moçambique e se desenvolvam juntamente (MACHEL, 1979, apud LOPES, SITOE e NHAMUENDE, 2002). Cabe salientar que alguns cursos de Letras ministrados na Universidade Eduardo Mondlane (UEM) e na Universidade Pedagógica (UP) já possuem nos seus currículos uma disciplina sobre o estudo das línguas moçambicanas e é desejável que gradualmente esse processo se alastre para outros cursos naquelas instituições. 
A par disso, não se vê razão para não introduzir a disciplina de línguas bantu de Moçambique ou não usar essas línguas como auxílio nas classes subsequentes ao ensino primário. É preciso que o modelo de educação bilíngue adotado para o ensino primário ( $1^{\mathrm{a}}$ a $7^{\mathrm{a}}$ classe) em Moçambique preveja a continuidade do uso dessas línguas a partir do $8^{\circ}$ ano de escolaridade ( $8^{\text {a }}$ classe) em diante, respeitando os direitos universais plasmados na DUDL, no uso adequado de todas as línguas faladas pelos moçambicanos.

A terceira constatação que se faz ao modelo de transição gradual adotado refere-se aos resultados das recentes avaliações do programa de ensino bilíngue. São estudos que têm relatado problemas referentes à implementação das políticas de separação das línguas em ação, por parte dos professores, tanto na fase de transição gradual da L1 para L2 como meios de ensino ( $3^{\mathrm{a}}$ e $4^{\mathrm{a}}$ classe), assim como na alternância dos códigos (codeswitching) dentro da sala de aulas a partir da $4^{\mathrm{a}}$ classe. Avaliando a execução do programa de educação bilíngue em casos do uso da L1 tanto em turmas de educação bilíngue como em contextos de ensino e aprendizagem de/em Português/L2, Chimbutane constatou:

[...] parece que, para muitos professores, a vertente de separação de línguas soa mais alto do que a de convivência de línguas no mesmo espaço de sala de aula. Uma das evidências que sustentam esta análise é o facto de alguns professores banirem ou evitarem o uso da alternância de códigos quer nos contextos de ensino/aprendizagem, de/em L1, quer processo de ensino/aprendizagem de/em L2, quer nos contextos de ensino/aprendizagem de/em Português/ L2. (CHIMBUTANE, 2015 [2013], p. 12-13)

Para a transição gradual, o autor salienta que as dificuldades dos alunos em não atingir desempenho satisfatório em português, podem ser claramente verificadas na fase de transição, quando o português passa a ser a língua de ensino/ aprendizagem. Percebe-se que a transição de meio de instrução do aluno (L1 para L2) no modelo de ensino bilíngue acontece prematuramente, pois na terceira classe ( $3^{\mathrm{a}}$ classe) a criança ainda não possui competências linguísticas e comunicativas da L2 suficientes para assimilar a matéria nesta língua. Mas, se o aluno tivesse as duas línguas como disciplinas e como meio 
de ensino desde o primeiro ano de escolaridade, tais situações seriam evitadas.

Commins e Baker já haviam antecipado sobre as consequências na escolha não adequada de um modelo bilíngue transicional para certos contextos. Para estes autores,

os programas de educação bilíngue de transição precoce são [...] ineficientes ao desenvolvimento da competência linguística e das competências acadêmicas e cognitivas que permitam aos alunos aprender em contextos linguísticos e academicamente exigentes em L2, resultando no insucesso escolar (COMMINS, 1984; BAKER, 1995, apud CHAMBO, 2014, p. 226).

Isso significa que resultados positivos de aprendizagem na L2 como língua de instrução dependem das habilidades linguísticas já adquiridas no uso da L1 como meio de ensino. Se estas forem fracas, fracassam também os resultados daquela.

Os alunos submetidos à educação bilíngue em Moçambique precisam ter uma base sólida das competências na L2, que não é a sua língua de escolarização primária, para depois seguir com o processo de transição. Assim, o modelo de bilinguismo inicial que incentiva o uso das duas línguas (L1 e L2) desde o primeiro ano de escolaridade ajudaria não somente a assimilação da matéria por parte dos alunos, mas também a transição em simultâneo das competências nessas línguas. Assim, o professor lidaria com a alternância de código já no começo do processo de ensino e aprendizagem.

À luz desta percepção, Chimbutane (2015 [2011], p. 20), diz que "os professores assumem que evitar ou desencorajar o uso da L1 dos alunos na sala de aulas, ao mesmo tempo em que se maximiza o uso do português/língua alvo, é a melhor forma de inverter a tendência negativa em termos de desempenho dos alunos nesta língua" nas fases de transição gradual do modelo adotado.

Os estudos dos autores acima e de outros vêm provar mais uma vez os problemas que o modelo de transição gradual em curso no ensino bilíngue em Moçambique pode (e está a) causar. Chimbutane (2015, p. 13) termina dizendo que "as diferenças de abordagem manifestada pelos diferentes professores do ensino bilíngue podem ser consequência de alguma falta de clareza sobre os mecanismos de operacionalização da política linguística educativa vigente", principalmente na execução do modelo bilíngue adotado na fase de transição gradual. 
Ainda a respeito da problemática da alternância do meio de instrução, Chambo diz que

os estudos sobre educação bilíngue [modelo adotado] incidem sobre aspectos linguísticos no ensino e aprendizagem (L1 e L2) e, portanto não abordam as questões culturais na pedagogia da educação bilíngue. A educação intercultural vai para além da questão linguística.(CHAMBO, 2014, p. 226)

Ou seja, quando analisado no completo, o programa de educação bilíngue em curso não inclui aspectos culturais das crianças, centrando-se, apenas, em questões linguísticas, especialmente na gramática.

Não basta entulhar matérias sobre a gramática da L2 no cérebro do aluno, sem considerar os aspectos culturais da sua L1. Por exemplo, implicitamente, com ajuda das atividades desenvolvidas em casa com a família, a criança sabe somar e subtrair as coisas. Portanto, é preciso estabelecer uma ponte entre as atividades culturais que o aluno aprende em casa e as matérias introduzidas na escola. É preciso estabelecer uma interligação entre as comunidades, a escola e a família no processo de ensino e aprendizagem; incluir conteúdos culturais nos programas das disciplinas, aproveitando estratégias e métodos de ensino culturais da comunidade e é preciso usar L2 e L1 como meios de instrução, bilinguismo inicial (desde o primeiro ano de escolarização), em simultâneo (CHAMBO, 2014) para promover um bilinguismo equilibrado.

Mais do que oferecer ao aluno um bom modelo de ensino para aprendizagem e incluir a sua língua materna na sua educação até o ensino fundamental e médio, é preciso disporlhe material escolar da sua língua para o auxílio às aulas programadas. Também deve-se incentivar a continuação de produção e disponibilização de materiais de ensino em línguas locais bantu que, sabe-se, já existe. A propósito dessa matéria, Paula e Quiraque sublinharam que

já existem naquele país, desde 2008, um total de quatrocentos e vinte e dois (422) títulos de livros de educação bilíngue (do aluno e do professor) produzidos em 17 línguas moçambicanas, para o primeiro e o segundo ciclos de ensino primário $\left(1^{\mathrm{a}}\right.$ e $2^{\mathrm{a}}$ classes, $3^{\mathrm{a}}, 4^{\mathrm{a}}$ e $5^{\mathrm{a}}$ classes, respectivamente). [...] E, ainda, temos a certeza de que já estão, desde 2010, elaborados e traduzidos para 17 línguas bantu de Moçambique, livros de educação bilíngue (do aluno e do professor) para o terceiro ciclo de ensino ( $6^{\mathrm{a}}$ e $7^{\mathrm{a}}$ 
classes) e minidicionários bilíngues de ciências naturais e de matemática para a sua publicação por parte dos órgãos competentes. (PAULA; QUIRAQUE, 2016, p. 1234)

É imprescindível que o MINEDH e outros que cuidam das matérias de ensino e aprendizagem no país reforcem o conteúdo de formação inicial de professores primários nos IFPs, instruindo-os sobre a utilização da alternância dos códigos de ensino (língua bantu e português) no processo de ensino e aprendizagem para que o aluno assimile a matéria ensinada. Sobretudo, é preciso que ocorra a capacitação contínua de professores primários em exercício, na matéria de pedagogia e didática de ensino de/em línguas em contextos bilíngue e multilíngue, pois se sabe que, quanto a sua formação, os IFPs ainda não tinham a disciplina de línguas bantu e metodologias de educação bilíngue.

\section{Considerações finais}

O presente trabalho objetivou discutir questões de diversidade e planificação linguísticas, concretamente sobre a escolha da língua de instrução para o processo de ensino e aprendizagem em Moçambique, à luz dos direitos linguísticos universais do cidadão propostos pela UNESCO (1996). Para tanto, foram apresentados e discutidos os direitos propostos na Declaração Universal dos Direitos Linguísticos e questões de política linguística de Moçambique e descritos os dois modelos de educação bilíngue vigentes, apresentando os pontos positivos e os fracassos na sua execução.

Reconhece-se a iniciativa do governo através do MINEDH nos projetos pilotos de ensino bilíngue levados a cabo e a introdução oficial, a partir de 2017, nas escolas que necessitam deste tipo de ensino. Ao mesmo tempo, urge que se repense seriamente o modelo de ensino adotado que, para ser bem assegurado, defendeu-se a introdução, em médio prazo, de um modelo que privilegia um bilinguismo inicial (LOPES, 1997).

Esse modelo prevê a utilização, desde o início da escolaridade do aluno, de uma língua bantu e do português como meios de ensino e disciplinas, e que os contextos de alternação desses meios dependam de cada local. Além de se evitar um desequilíbrio nas competências linguísticas e comunicativas da L1 e L2, sobretudo desta última, o modelo 
de bilinguismo inicial ajudaria o professor a lidar com a alternância do código de ensino logo no começo do processo de ensino aprendizagem. Assim, algumas consequências, como a preferência de um código em detrimento do outro quando inicia a alternância no meio do processo de escolarização como prevê o atual modelo, poderiam ser evitadas.

Nesse sentido, também seria um modelo que incluiria a disciplina de línguas bantu nas classes subsequentes ao ensino básico $\left(8^{\circ}\right.$ a $\left.12^{\circ}\right)$, inclusive no ensino superior, de modo que, em médio prazo, as línguas bantu e o português falado em Moçambique cresçam lado a lado, rumo ao desenvolvimento do país.

Ao MINEDH cabe intensificar a formação inicial de professores primários em pedagogia e didática de ensino bilíngue e investir na formação contínua dos professores em exercício. Por seu turno, à UEM e à UP e outras, caberia continuar a formação de pesquisadores e formadores de professores primários na matéria de estudo e ensino de línguas bantu, cuidando, nessas formações, de assegurar que a (re)construção da cidadania e da unidade nacional entre os moçambicanos, como um processo contínuo, só será possível quando as suas línguas forem valorizadas e respeitados os direitos linguísticos do cidadão, como protagoniza a UNESCO.

\section{REFERÊNCIAS}

BENSON, C. J. Relatório Final sobre o Ensino Bilíngue: resultados da avaliação externa da experiência de escolarização Bilíngue em Moçambique. Maputo: INDE, 1997.

CAPUCHO, M. F. Sobre Línguas e Culturas. Veredas - Revista de Estudos Linguísticos. v. 10, $\mathrm{n}^{\mathrm{o}} 1$ e 2. 2006. Disponível em: <http://www.ufjf.br/revistaveredas/files/2009/12/artigo094. pdf $>$. Acesso em 05 jul. 2015.

CHAMBO, G. A. Pedagogia Intercultural na Educação Bilíngue em Moçambique: uma proposta metodológica. In: NGUNGA, A. (Ed.). Temas de Gramáticas de Linguas Bantu I. Col. "As Nossas Línguas XIII". Maputo: CEA-UEM, 2014. 
CHIMBUTANE, F. S. O Uso da L1 dos alunos como recurso no processo de ensino e aprendizagem de/em Português/L2: o contexto de ensino bilíngue em Moçambique. Rev. Cient. UEM: Sér. ciênc. soc. v. 1, n. 1. p. 7-25. 2015. Disponível em: <http:// www.revistacientifica.uem.mz/index.php/seriec/article/ view/92/53> Acesso em: 6 maio 2016.

DIAS, H. N. As desigualdades sociolinguísticas e o fracasso escolar: Em direção a uma Prática Linguístico-Escolar Libertadora. Maputo: Promédia, 2002.

FIRMINO, G. Diversidade linguística e desenvolvimento nacional: questões sobre politica linguística em Moçambique. Rev. Cient. UEM: Sér. ciênc. soc. v. 1, n. 1. p. 121-132. 2015. Disponível em: <http://www.revistacientifica.uem.mz/index. php/seriec/article/view/98/59> Acesso em: 6 maio 2016.

INTITUTO NACIONAL DE ESTATÍSTICA. Moçambique Projecções 2007-2040. Disponível me: <http://www.ine.gov.mz>. Acesso em: 26 de jun. 2016.

INDE. Programa de educação bilingue para o II ciclo do ensino básico. Maputo - Moçambique. Disponível em: <http://docplayer.com. br/9714324-Programa-de-educacao-bilingue-para-o-ii-ciclodo-ensino-basico.html> Acesso em: 22 dez. 2016.

LOPES, A. J. Política Linguística: princípios e problemas. Maputo: Livraria Universitária, 1997.

; SITOE, S. J.; NHAMUENDE, P. J. Moçambicaníssimos: para um léxico de usos do Português Moçambicano. Livraria Universitária: Maputo-Moçambique, 2002.

MABASSO, E. Estratégias linguístico-discursivas na investigação criminal: o caso das esquadras de Maputo. 2010. 342 fls. Tese (Doutorado em Linguística) - Faculdade de Letras e Ciências Sociais, Universidade Eduardo Mondlane, Maputo, 2010.

Língua oficial, direito positivo e direito costumeiro nas Esquadras de Moçambique: Um caso para a linguística forense. Rev. Cient. UEM: Sér. ciênc. soc. v. 1, p. 21-39. 2012. Disponível em: <http://www.revistacientifica.uem.mz/index.php/seriec/ article/view/17/29> Acesso em: 6 maio 2016.

MOÇAMBIQUE. Constituição da República de Moçambique. Maputo, 2004. 
NGUNGA, A.; BAVO, N. Práticas Linguísticas em Moçambique: Avaliação da vitalidade linguística em seis distritos. Col. "As Nossas Línguas IV". Maputo: CEA, 2011.

PATEL, S. A. Olhares sobre a educação bilingue e seus professores em uma região de Moçambique. Campinas/SP - 2006. 121fls. Dissertação (Mestrado em Linguística Aplicada na área de Ensino-Aprendizagem de Segunda Língua e Língua Estrangeira) - Instituto de Estudos de Linguagem, Universidade Estadual de Campinas, Campinas-SP, 2006.

PAULA, M. H. de; QUIRAQUE, Z. A. S. A necessidade de uma política linguística inclusiva para o multilinguismo em Moçambique. Domínios de Lingu@gem, Uberlândia. vol. 10, n. 4, p. 1220-1237, out./dez. 2016. Disponível em: <http:// www.seer.ufu.br/index.php/dominiosdelinguagem/article/ view/34575/19261>. Acesso em: 4 dez. 2016.

SITOE, B. A produção, promoção e divulgação em línguas bantu moçambicanas: bulu na mufundhisi Bento Sitoe. (Entrevista a A. A. Timbane e E. A. C. Nhampoca). Linguagem - estudos e pesquisas. vol. 20, n. 2, p. 1-14, jul./dez. 2016. Disponível em: <revistas.ufg.br/lep>. Acesso em: 15 jan. 2017.

UNESCO. Declaração Universal dos Direitos Linguísticos. Tradução de Wanda Ramos. Florianópolis/SC: FENEIS, 1996. Tradução de: Universal Declaration of Linguistic Rights. Disponível em: $<$ http://portal.sme.prefeitura.sp.gov.br/Portals/1/Files/20259. pdf> Acesso em: 27 abr. 2016

UACIQUETE, A. S. Modelo de Administração de Educação em Moçambique (1985-2009). Maputo: Texto Editora. 2011. 


\section{Abstract \\ Linguistic diversity, language rights and linguistic planning in Mozambique: problems and challenges in the adoption of the language of instruction in teaching and learning process}

Mozambique is a multilingual, plurilingual and multicultural country, where around twenty languages are classified as Bantu, with their specific characteristics but correlated. Between these languages, the most spoken is used by $26.1 \%$ of the population, which is one of the reasons why Mozambique is among the twenty-five African countries with high linguistic diversity. In this context, the question for our study is: what language to adopt for teaching to respect the linguistic rights of each individual to receive education in his mother tongue. To answer this question, (1) we discuss the adoption of Portuguese as the only language of teaching and subject since the post-independence period; (2) we analyzed critically the two models of education (monolingual and bilingual) that has being used in Mozambique and; also (3) we propose the strategy to improve the teaching and learning process of the country. Bibliographical research and introspection was the method we used to support the study, based in the position that Mozambique needs a model that promotes an initial bilingualism from the first years of schooling, prevising the continuity of the use of Bantu languages in the subsequent primary classes of education. In this perspective, it is necessary to instill a strong or concrete knowledge in the trainees of the Institutes of Teacher Training in matter of bilingual education, without forget to train the actual teacher in the same field, to guarante to the Mozambican citizen, to enjoy part of the linguistic rights established in 1996 by the United Nations Educational, Scientific and Cultural Organization (UNESCO).

Keyword: Linguistic diversity, Language rights, Language of instruction. 